\title{
Spatial-Temporal Distribution of the Palinurid and Scyllarid Phyllosoma Larvae in Oman Coastal Waters
}

\author{
Sergey Khvorov ${ }^{1 *}$, Sergey Piontkovski ${ }^{2}$, and Elena Popova ${ }^{3}$ \\ ${ }^{1}$ Marine Science Fisheries Centre, Ministry of Agriculture and Fisheries Wealth \\ P.O. Box 227, Sultanate of Oman \\ ${ }^{2}$ College of Agricultural and Marine Sciences, Sultan Qaboos University \\ P.O. Box 34, Al-Khod 123, Sultanate of Oman \\ ${ }^{3}$ Institute of Biology of the Southern Seas, 2, Nakhimov av.-Crimea \\ 99011, Sevastopol, Ukraine

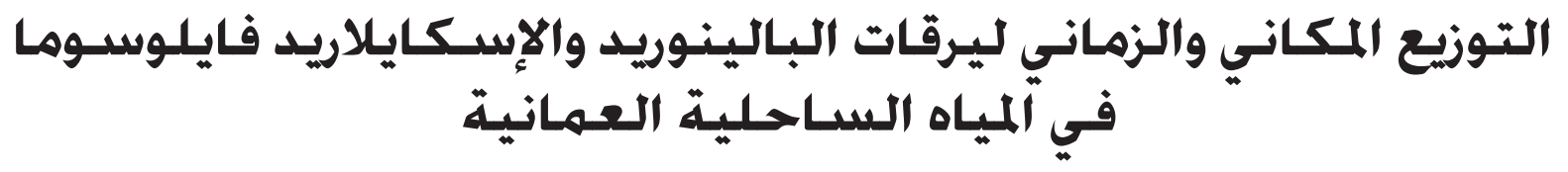 \\ سيرجي خـفوروف وسيرجي بيـونتكوفسكي والينـا بوبوفا

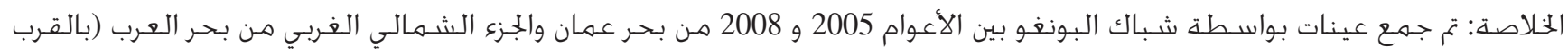

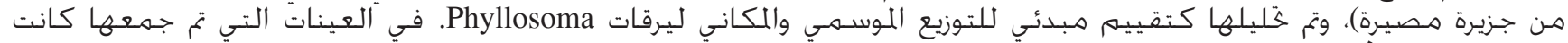

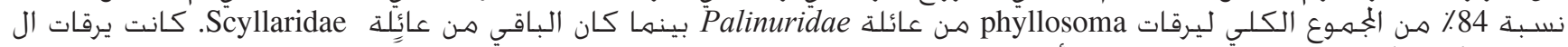

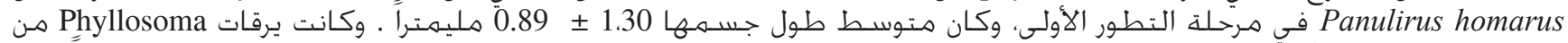

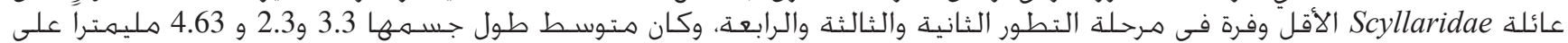

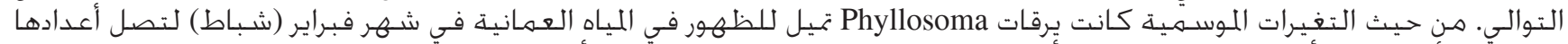

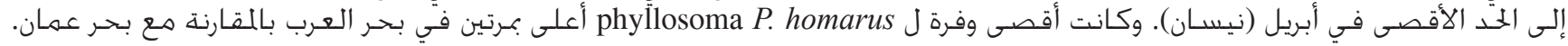

$$
\text { كلمات مفتاحية: بحـر العرب، عوالق حيوانية ،يرقات }
$$

ABSTRACT: The Bongo Net samples collected between 2005 and 2008 in the Sea of Oman and in the north-western part of the Arabian Sea (near Massirah Island) were analyzed, for a pilot assessment of seasonal and spatial distribution of the phyllosoma larvae. In the samples collected, $84 \%$ of all phyllosoma larvae were from the family Palinuridae, while the others were contributed by family Scyllaridae. All larvae of Panulirus homarus were in the first development stage and had a mean body length of $1.30 \pm 0.89 \mathrm{~mm}$. The phyllosoma larvae of the less abundant family Scyllaridae were in the second, third, and fourth development stages, which had a mean length of $2.3 \mathrm{~mm}, 3.3 \mathrm{~mm}$ and $4.63 \mathrm{~mm}$, respectively. In terms of seasonal changes, the phyllosoma larvae tend to appear in Omani waters in February, reaching their maximum numbers in April. The abundance of phyllosoma P. homarus was as much as twofold higher in the Arabian Sea compared to the Sea of Oman.

Keywords: Arabian Sea, zooplankton, larvae.

\section{Introduction}

Lobsters (family Palinuridae and Scyllaridae) are a valuable fisheries resource in the coastal waters of Oman comprising primarily one species- Panulirus homarus (Linnaeus, 1878) (spiny lobster). Geographically, the species is distributed from the Dhofar region in the south of the country to the Sea of Oman waters, in the north. Landings of spiny lobster declined, from 2000t in 1980s to 407t in 2010 (Fishery Statistics Books 1999-2010; Fig.1). Overfishing, increased occurrence of harmful algal blooms and fish-kill incidents were all factors in this decline. All fit the same trend reported for the Omani coastal waters (Piontkovski et al., 2012; Sheppard et al., 2010), although the mechanisms of physicalbiological coupling mediating these trends have yet to be evaluated.
To reach maturity, a spiny lobster has to pass through a number of development stages, starting from the phyllosoma larvae. In this regard, regular field surveys of the phyllosoma larvae number along the coast are of great importance if we are to understand the spatial-temporal characteristics of population recruitment. The larvae may be carried long distances by currents. This results in the settlement taking place far away from breeding grounds (Lewis, 1951).

In analyzing data of annual plankton surveys we aimed to initiate pilot assessment of seasonal and spatial distribution of the phyllosoma larvae along the Omani coast.

\section{Materials and Methods}

Coastal survey has resulted in 118 samples collected between 2005 and 2008 in two regions (Fig. 2). The first one was 


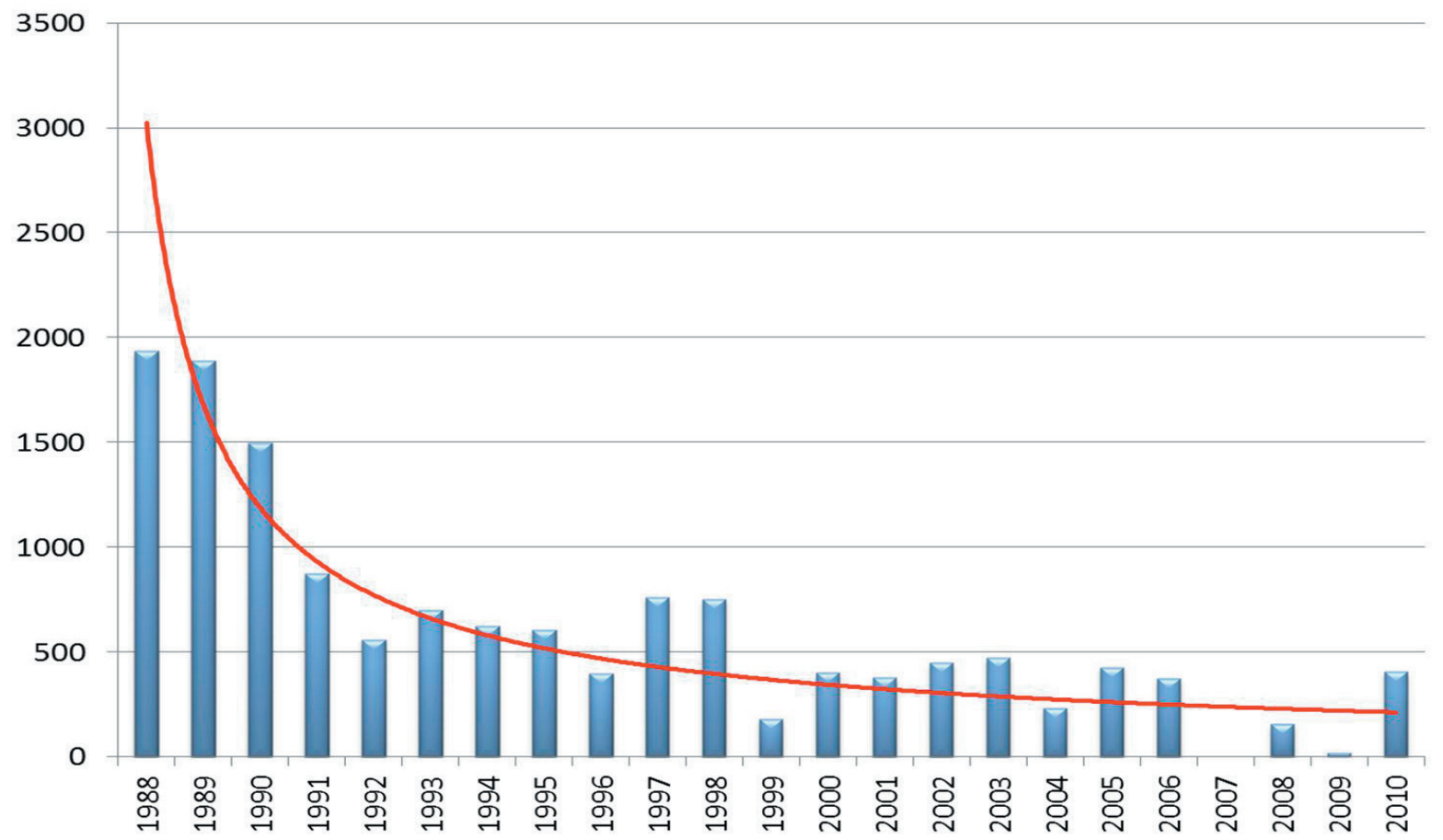

Figure 1. Reported catches of Panulirus homarus in Omani waters from 1988 to 2010 (metric tons).

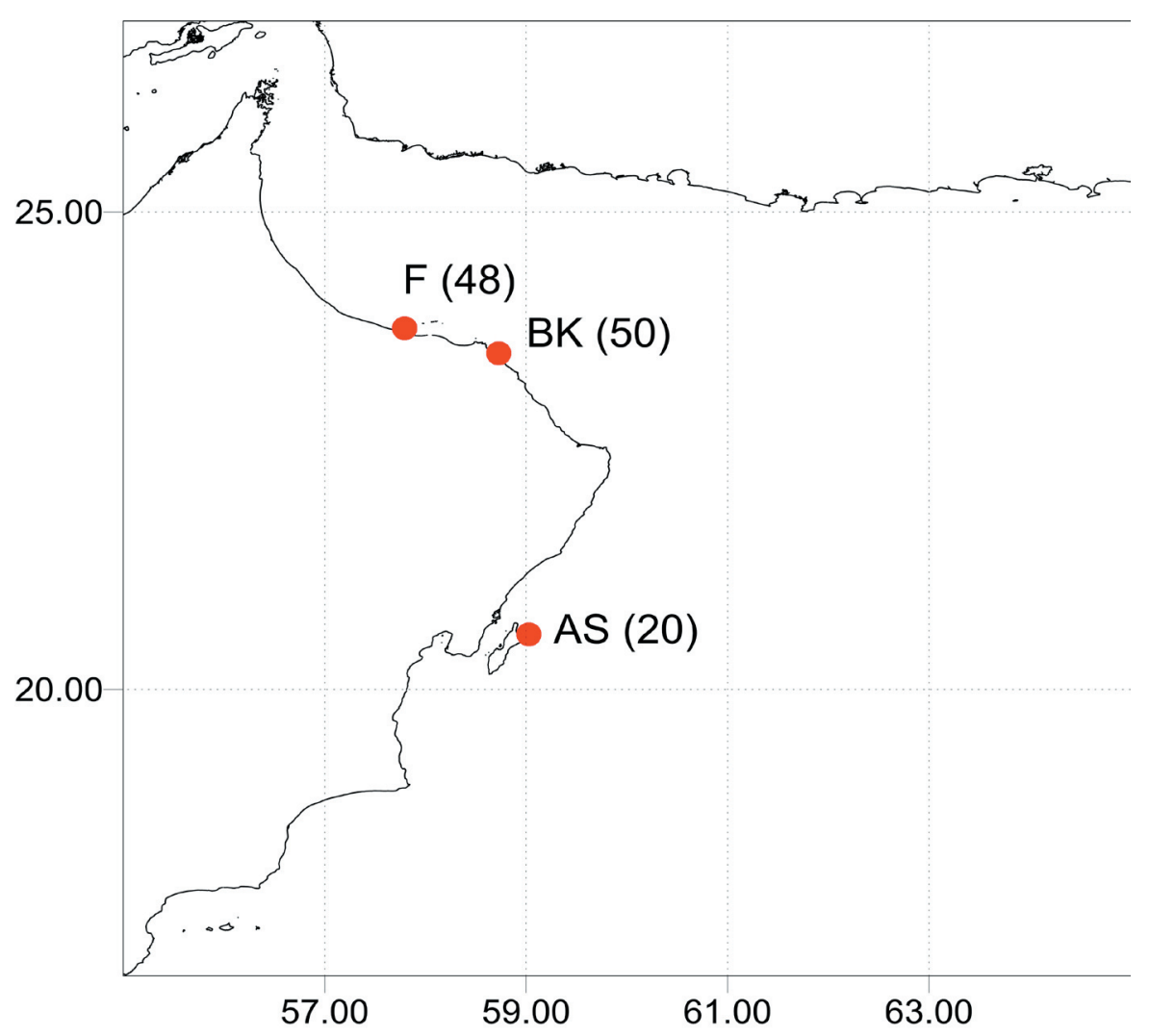

Figure 2. Sampling sites, with the total number of zooplankton samples collected (in brackets). 


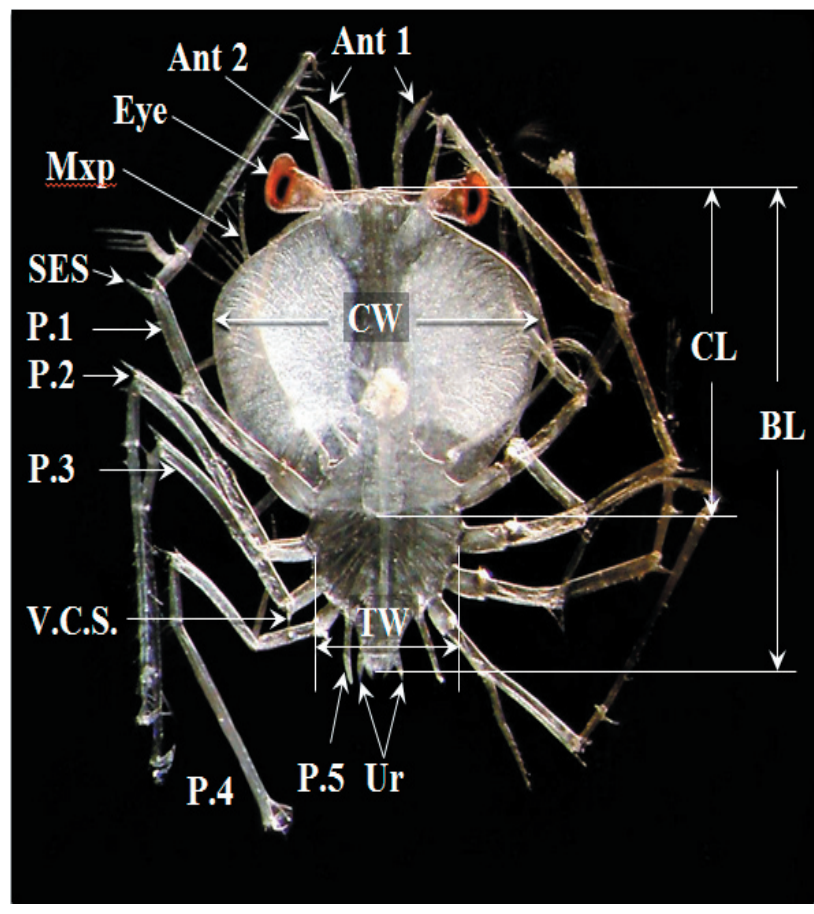

Figure 3. Morphometric characteristics of phyllosoma larvae. Morphology: Ant.1 - antennule; Ant. 2 - antenna; Mxp - maxilliped 3; P.1 - P.5 - $1^{\text {st }}-5^{\text {th }}$ pereiopods; Uro uropod, V.C.S - ventral coxal spine; S.E.S. - sub-exopodal spine. Measurements: BL - body length; CL - cephalic length; CW - cephalic width; TW -thorax width. located in the Sea of Oman near Muscat, with a sampling site in Bandar Al Khayran Bay (BK) and near Fakhal Island $(\mathrm{F})$. The second one was located in the northwestern part of the Arabian Sea, near Massirah Island (stations AS).

A Bongo net (with $150 \mu \mathrm{m}$ mesh size and $0.4 \mathrm{~m}$ diameter) was equipped with the water flow ("Hydrobios") counter. Samples were preserved with $4 \%$ formalin. In the lab, these samples were sub-sampled by a Motoda or Folsom box splitter and sorted out into taxonomic groups identified to the lowest taxon possible.

Taxonomical identification of the phyllosoma larvae was based on a number of manuals (Berry, 1974; Sekiguchi, 1986b; Johnson, Allen, 2005; Chow et al., 2006; Coutures, 2001, Barnett et al., 1984). The morphometric characteristics used were the length of the cephalic shield, the total body length, the width of cephalon and thorax (Fig. 3). Furthermore, the ratios of length to width for body parts and appropriate morphometric coefficients (Robertson, 1969; Sekiguchi, 1986b) were calculated (Table 1). Identification of the developmental stage has incorporated examination of eyes, antenna, and abdomen shape (Berry, 1974; Braine et al., 1979; Minami et al., 2001).

The ICES Zooplankton Methodology Manual was used, to estimate the abundance of phyllosoma larvae in samples (Harris et al., 2000). The abundance is calculated by $\mathrm{N}=(n k) / \mathrm{m}^{3}$, where $n$ is the abundance of organisms in a sub-sample $k$ of the collected sample.

Table 1. Morphometric characteristics of developmental stages.

\begin{tabular}{|c|c|c|c|c|c|c|c|c|c|}
\hline \multirow{2}{*}{ Taxon } & \multirow{2}{*}{ Stage } & \multirow{2}{*}{ Instar } & \multirow{2}{*}{$\begin{array}{c}\text { Specimen } \\
\text { ID }\end{array}$} & \multicolumn{4}{|c|}{ Measurements } & \multicolumn{2}{|c|}{ Ratios } \\
\hline & & & & $\mathrm{BL}$ & $\mathrm{CW}$ & $\mathrm{CL}$ & TW & $\mathrm{CL} / \mathrm{CW}$ & $\mathrm{CT}$ \\
\hline \multirow{16}{*}{$\begin{array}{l}\text { Panulirus } \\
\text { homarus }\end{array}$} & \multirow{16}{*}{ Stage 1} & \multirow{2}{*}{1} & AS/I/1.3 & 1,13 & 0,78 & 0,60 & 0,45 & 0.77 & 0.58 \\
\hline & & & AS/I/2a.2 & 1,13 & 0,70 & 0,60 & 0,40 & 0.86 & 0.57 \\
\hline & & \multirow{2}{*}{2} & $\mathrm{BK} / \mathrm{I} / 6$ & 1,18 & 0,78 & 0,75 & 0,43 & 0.96 & 0.55 \\
\hline & & & $\mathrm{AS} / \mathrm{I} / 2 \mathrm{~b}$ & 1,20 & 0,88 & 0,78 & 0,45 & 0.89 & 0.51 \\
\hline & & \multirow{3}{*}{3} & $\mathrm{AS} / \mathrm{I} / 2 \mathrm{c}$ & 1,27 & 0,75 & 0,75 & 0,38 & 1.0 & 0.51 \\
\hline & & & AS/I/3 & 1,28 & 0,63 & 0,68 & 0,45 & 1.08 & 0.71 \\
\hline & & & AS/I/9.4 & 1,28 & 0,60 & 0,70 & 0,48 & 1.17 & 0.8 \\
\hline & & \multirow[t]{3}{*}{4} & $\mathrm{AS} / \mathrm{I} / 8.1$ & 1,33 & 0,70 & 0,75 & 0,45 & 1.07 & 0.64 \\
\hline & & & AS/I/9.2 & 1,33 & 0,75 & 0,78 & 0,50 & 1.04 & 0.67 \\
\hline & & & $\mathrm{BK} / \mathrm{I} / 7 \mathrm{~b}$ & 1,35 & 0,70 & 0,75 & 0,50 & 1.07 & 0.71 \\
\hline & & \multirow[t]{3}{*}{5} & AS/I/9.1 & 1,35 & 0,78 & 0,65 & 0,45 & 0.83 & 0.58 \\
\hline & & & AS/I/9.3 & 1,35 & 0,75 & 0,68 & 0,50 & 0.91 & 0.67 \\
\hline & & & AS/I/2a.1 & 1,38 & 0,73 & 0,75 & 0,50 & 1.03 & 0.68 \\
\hline & & \multirow[t]{2}{*}{6} & $\mathrm{AS} / \mathrm{I} / 4$ & 1,38 & 0,70 & 0,73 & 0,48 & 1.04 & 0.69 \\
\hline & & & $\mathrm{AS} / \mathrm{I} / 8.2$ & 1,38 & 0,70 & 0,83 & 0,45 & 1.19 & 0.64 \\
\hline & & 7 & AS/I/1.1 & 1.48 & 0.78 & 0.83 & 0.55 & 1.06 & 0.71 \\
\hline \multirow{3}{*}{ Scyllaridae } & Stage II & & $\mathrm{AS} / \mathrm{II} / 5$ & 2,3 & 1,55 & 1,58 & 0,80 & 1.02 & 0.52 \\
\hline & Stage III & & $\mathrm{AS} / \mathrm{III} / 7 \mathrm{a}$ & 3,3 & 2,38 & 2,25 & 1,23 & 0.95 & 0.52 \\
\hline & Stage IV & & AS/IV/1.2 & 4,63 & 3,75 & 2,88 & 1,88 & 0.77 & 0.50 \\
\hline
\end{tabular}

BL - body length (mm); CW - cephalic width; CL - cephalic length; TW - thorax width; CT - ratio between CW and TW. 


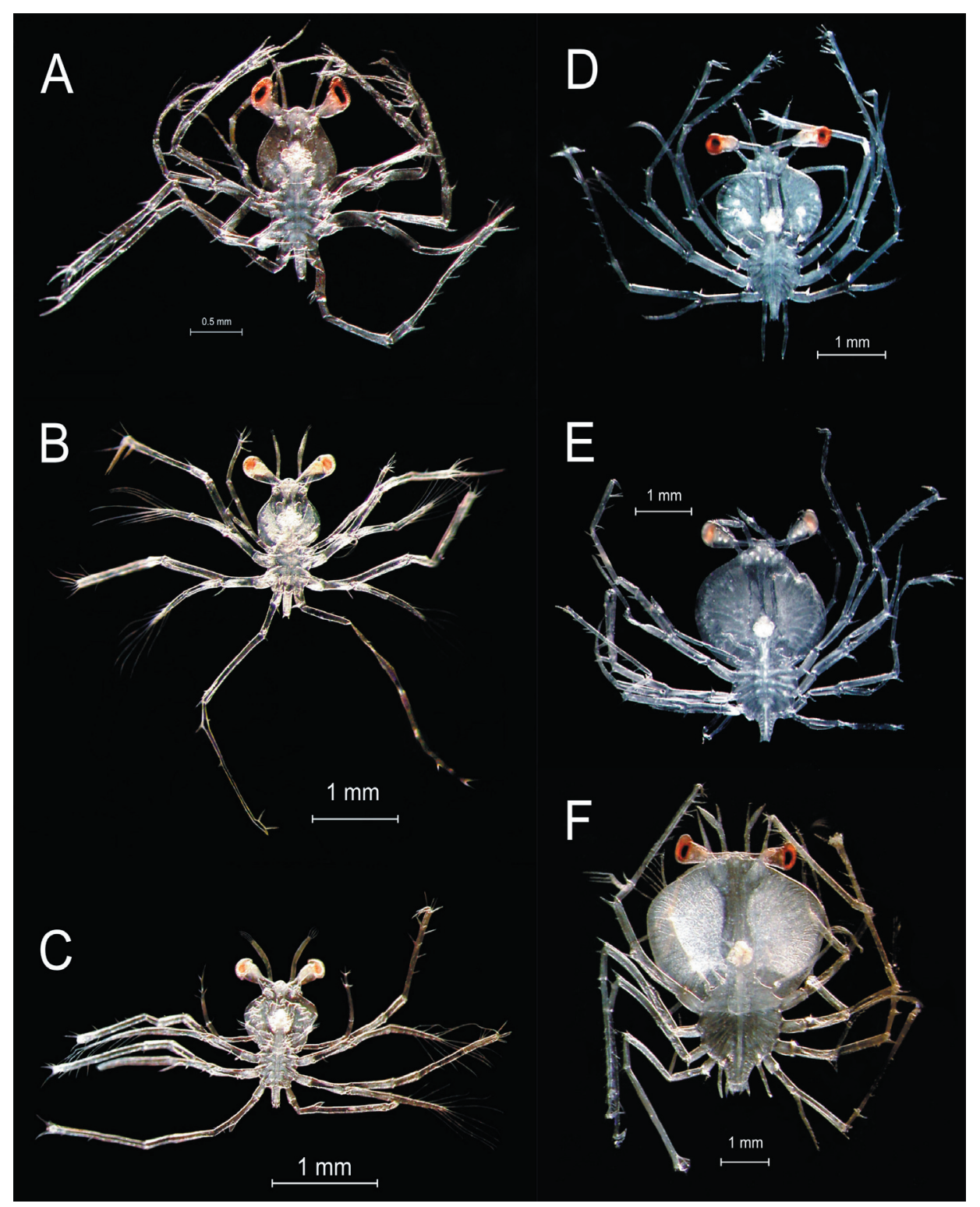

Figure 4. The phyllosoma larvae collected in Omani coastal waters. Palinurus homarus: A-A/S/I/1.1; B - AS/I/2a.1; C - AS/I/2a.2; Scyllaridae: D - AS/II/5; E - AS/III/7a; F - AS/IV/1.2.

Satellite derived (9-km spatial resolution SeaWIFS) Level-3 weekly data for chlorophyll $a$ concentration were used to retrieve maps of chlorophyll a in 2007. Spatial distribution of chlorophyll " $a$ " was acquired using the GES-DISC Interactive Online Visualization and Analysis Infrastructure software as part of the NASA's Goddard Earth Sciences Data and Information Services Center.

\section{Results and Discussion}

Omani coastal waters inhabited by phyllosoma larvae are subjected to gradual seasonal changes. The driving force of these changes is the monsoonal winds mediating the system of coastal currents. These currents experience dramatic changes resulting in total reversing of direction depending on the time and origin of monsoons. In summer (which is the time of the south-west monsoon), the Oman Coastal Current propagates northward, along the Omani coast. In winter, the winds of the north-east monsoon reverse the system of currents making the water mass transport oriented southward. The inter-monsoon periods (spanning the spring and fall), might be characterized as the time of reconstruction in the system of currents.

In the summer months of the south-west monsoon, productivity of the western Arabian Sea is at its maximum, due to Omani coastal upwelling. In winter, the north-east monsoon sets up the upwelling along the coast of Iran and Pakistan resulting in highly productive waters in the Sea of Oman and the northern Arabian Sea (Smith, 2005; Wiggert et al., 2009).

In the zooplankton samples collected, $84 \%$ of all phyllosoma larvae were from the family Palinuridae (Panulirus homarus), while the others were contributed by the family Scyllaridae (Fig. 4). All phyllosomas of P. homarus 


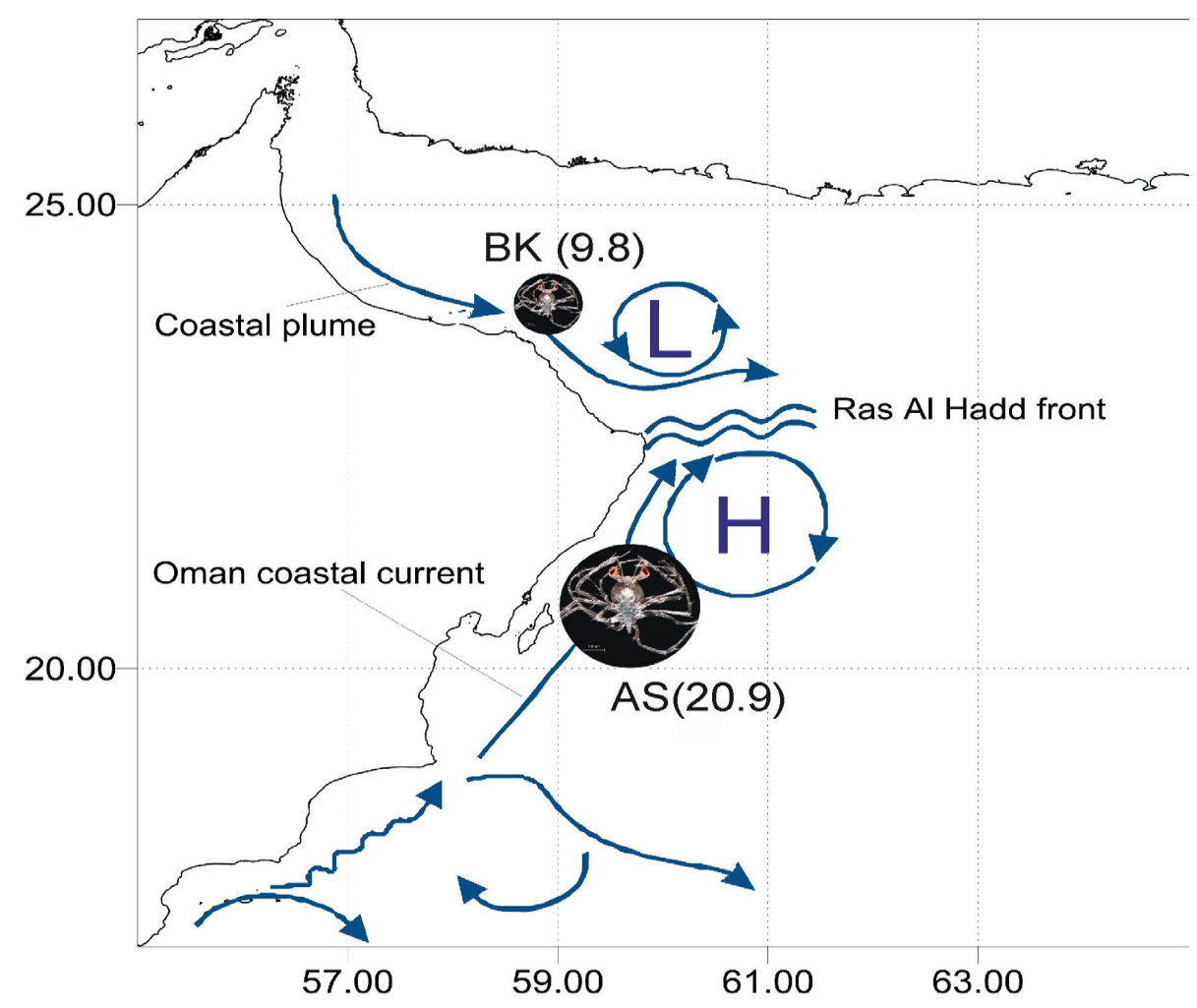

Figure 5. The abundance of phyllosoma larvae Palinurus homarus over sampling sites and a scheme of coastal currents.

Schematic diagram of coastal circulation during the southwest monsoon is a courtesy of the Rosenstiel School of Marine and Atmospheric Science, University of Miami (http://disc.sci.gsfc.nasa. gov/oceancolor/additional/science-focus/ocean-color/ras_al_ hadd_jet.shtml).

L-cyclonic eddy, H-anticyclonic eddy.

have had the first development stage. The body length varied between 1.13 and $1.48 \mathrm{~mm}$ and had a mean length of $1.30 \pm 0.89 \mathrm{~mm}$.

The phyllosoma larvae of the less abundant family Scyllaridae were at the second, third, and fourth development stage, which had a mean length of $2.3 \mathrm{~mm}$, $3.3 \mathrm{~mm}$, and $4.63 \mathrm{~mm}$, respectively.

At station AS in the Arabian Sea, the abundance of the $P$. homarus larvae $\left(20\right.$ ind $\left.\mathrm{m}^{-3}\right)$ was twofold higher that at station BK in the Sea of Oman (Fig. 5). Larvae of family Scyllaridae were found at station AS only, in relatively small numbers (1.6 ind. $\mathrm{m}^{-3}$ ).

In terms of seasonal changes, the phyllosoma larvae exhibited minimal abundance in winter (from December to February) and maximal values in May (Fig. 6). At that time, the peak is formed by the first development stage of $P$. homarus.

As far as the interannual changes are concerned, the variability of abundance over the years was quite high.
The phyllosoma larvae were not found in the samples collected in 2005 and 2008. The most productive (in terms of larvae abundance) was in 2007 (Fig. 6).

In using the Bongo nets to catch the phyllosoma larvae, we rested on a previous successful application of this type of nets to sample macroplanktonic crustaceans (Pepin and Shears, 1997). The phyllosoma larvae caught - all had the non-segmented antennula, antenna, and eyes. These features allow larvae to be attributed to the first development stage. The body length of this stage varied, from 1.13 to $1.48 \mathrm{~mm}$ (Table 1 ). This means that organisms could belong to different species or, the same development stage might have a broad size range, due to intensive growth rate but long development period.

In spite of numerous reports on phyllosoma biology and ecology (Phillips et al., 1981; Sekiguchi, 1986a; Kathirvel, 1990; Yeung et, al., 1995; Inoue et al., 2001; Minami et al., 2001; Inoue et al., 2004; ManzanillaDominguez and Gasca, 2004; Manzanilla-Dominguez and 


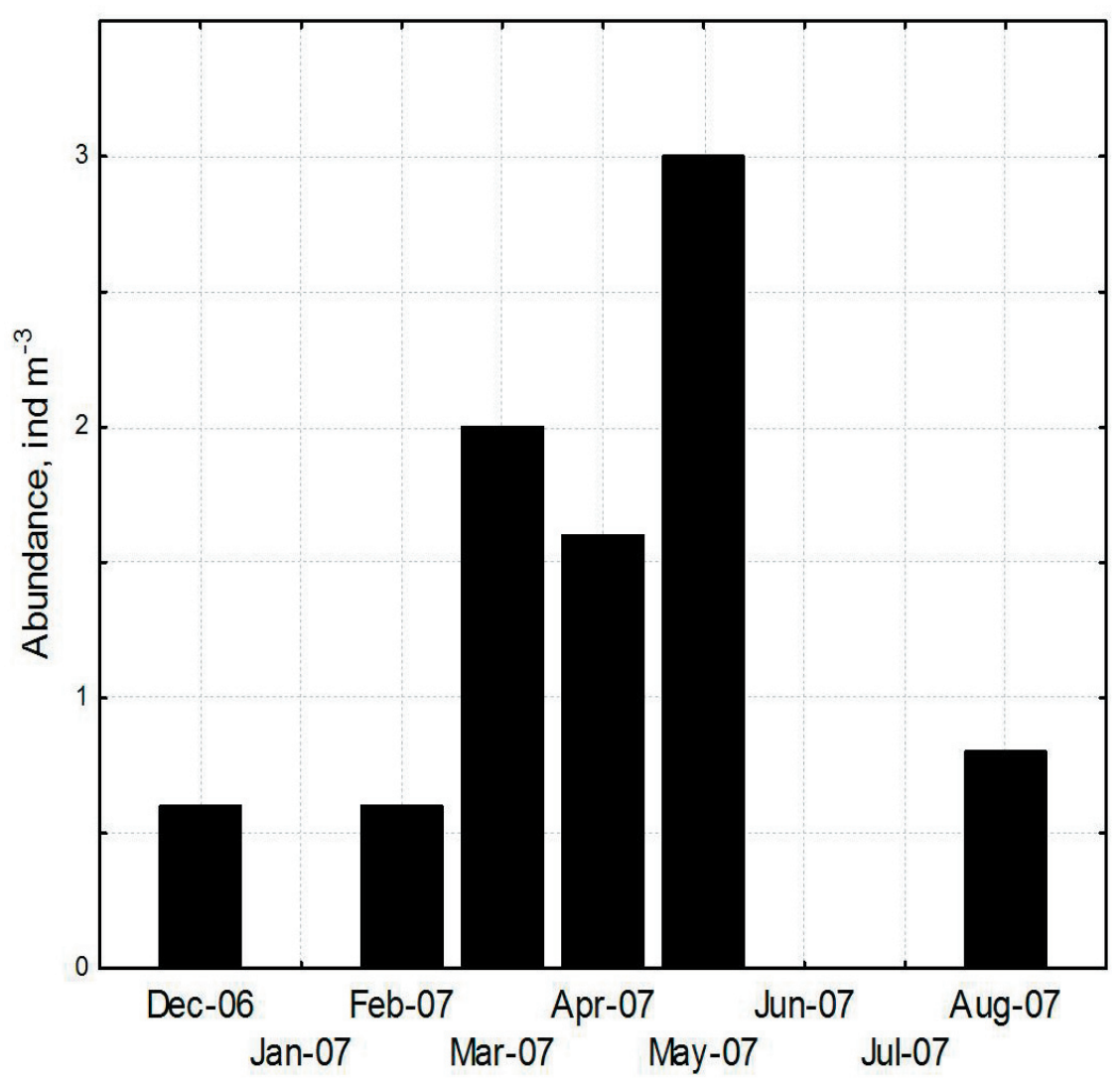

Figure 6. Seasonal changes of the abundance of phyllosoma larvae Panulirus homarus in the Arabian Sea (station AS).

Suárez-Morales, 2005), there is still a lack of quantitative estimates of abundance. We did not find published data for the phyllosoma abundance in the Sea of Oman. The data available nearby dealt with the Kuwait region, in which the abundance of phyllosoma larvae Thenus orientalis was 0.7 ind. $\mathrm{m}^{-3}$ (Al-Yamani and Khvorov, 2007).

In terms of comparative approach, the abundance reported for the other geographical regions of the world's ocean was much less. For instance, in coastal waters of Juan Fernandez Archipelago (Chilean islands, 33 40' S $78^{\circ} 50^{\prime} \mathrm{W}$ ) and Desventuradas Islands (26 $20^{\prime} \mathrm{S}-80^{\circ} 05^{\prime}$ $\mathrm{W})$ in the south-east Pacific, the abundance of phyllosoma larvae was 0.6 ind. $\mathrm{m}^{-3}$ (Mujica, 2006). In the coastal waters of South Africa, the abundance of phyllosoma P. homarus was 3 orders of magnitude less - 0.6 ind. $/ 1000 \mathrm{~m}^{3}$ (Berry, 1974). Our estimates are consistent with earlier reports on high concentration of larvae contributed by Palinura in the western Indian Ocean (Prasad et al., 1975).

As mentioned above the abundance of phyllosoma $P$. homarus was as much as twofold higher in the Arabian Sea compared to the Sea of Oman (Fig. 4). There might be a number of reasons for that. For instance, the productivity of the coastal waters of the western Arabian Sea in April and May 2007 was higher than the productivity of the coastal waters of the Sea of Oman (Fig. 7). This implies less favorable feeding grounds for the phyllosoma larvae in the Sea of Oman compared to the Arabian Sea.

In developing methods of the phyllosoma aquaculture, Igarashi and Kittaka (1994) stressed the importance of using microalgae. They reported that yearly-stage phyllosomas succeeded in prolonging their lives in culture water with microalgae, while the phyllosomas contained without microalgae survived for only few days.

Overall, the phyllosoma larvae are believed to be an opportunistic carnivore, whose diets correlate with the relative abundance of prey in the ambient water (Suzuki et al., 2008). In our case, data on mesozooplankton groups in samples did also imply high concentration of abundant zooplankton species in April and May, during the phyllosoma abundance peak. For instance, the copepods comprise about $70 \%$ of the mesozooplankton abundance of which Oithona brevicornis was one of the dominant species. In BK and AS regions, maximal concentration of this species was in April-May (Table 2).

Interestingly, peaks of phyllosoma abundance in both regions in 2007 were associated with the inter-monsoon season (April-May). The intermonsoon period is the time of minimal productivity in the western Arabian Sea. The reasons and mechanisms mediating this peculiarity of the phyllosoma seasonal cycle are yet to be found. More detailed field surveys are required. 
Chlorophyll Concentration - Apr 282007

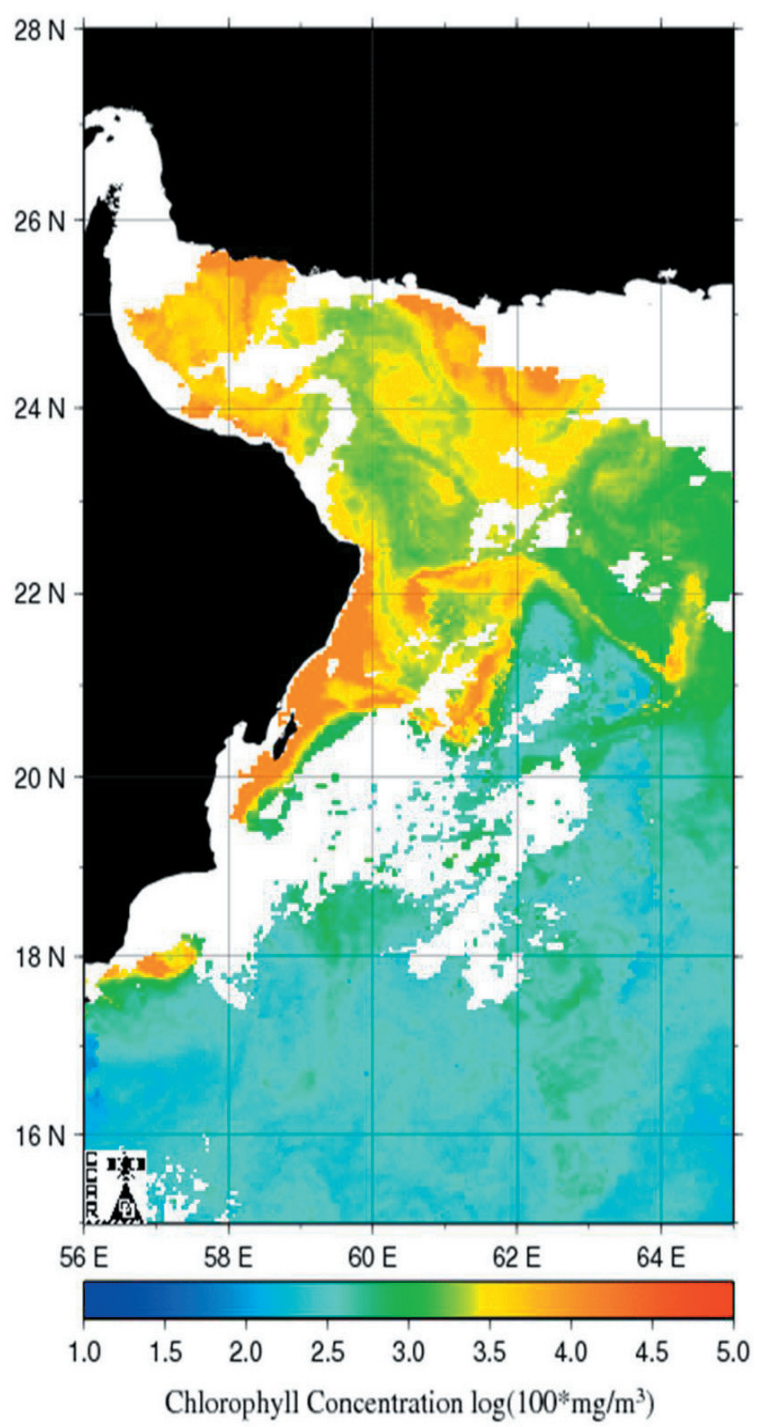

Figure 7. Remotely sensed distribution of chlorophyll $a$ in April, 2007 (SeaFIWS scanner).

\section{Acknowledgments}

We appreciate S. Smith, I. Prusova, A.Al-Azri and K.AlKhashmi for the samples provided to study the phyllosoma larvae.

This research was supported by the Research Council grant \# ORG/EBR/09/004 (Sultanate of Oman).

\section{References}

Al-Yamani, F.Y. and S.A. Khvorov. 2007. Spatial and temporal variability in larval decapod abundance in Kuwait's waters off Bubiyan Island. International Journal of Oceans and Oceanography 2:69-84.

Barnett, B.M., R.F. Hartwick, and N.E. Milward. 1984. Phyllosoma and Nisto stage of the Morton Bay Bug, Thenus orientalis (Lund) (Crustacea:Decapoda:
Table 2. Monthly changes of Oithona brevicornis abundance (ind. $\mathrm{m}^{-3}$ ) at $\mathrm{BK}$ and $\mathrm{AS} 1$ stations.

\begin{tabular}{lrcc}
\hline $\begin{array}{l}\text { Date } \\
\text { (mo./date/year) }\end{array}$ & BK & $\begin{array}{c}\text { Date } \\
\text { (mo./date/year) }\end{array}$ & AS1 \\
\hline $3 / 5 / 2007$ & 3,3 & $2 / 25 / 2007$ & 1,5 \\
$3 / 20 / 2007$ & 67,4 & $3 / 27 / 2007$ & 1,5 \\
$4 / 16 / 2007$ & 2,4 & $4 / 23 / 2007$ & 1,6 \\
$4 / 2 / 2007$ & 124,1 & $5 / 28 / 2007$ & 78,000 \\
$5 / 6 / 2007$ & 126,6 & $10 / 28 / 2007$ & 14,6 \\
$5 / 20 / 2007$ & 6,2 & $11 / 24 / 2007$ & 26,000 \\
$6 / 17 / 2007$ & 20,5 & & \\
$7 / 1 / 2007$ & 20,1 & & \\
$8 / 25 / 2007$ & 10,8 & & \\
\hline
\end{tabular}

Scyllaridae), from shelf waters of the Great Barrier reef, Australian Journal of Marine and Freshwater Research 35:143 -152.

Berry P.F. 1974. Palinurid and Scyllarid lobster larvae of the Natal coast, South Africa. Investigational Report, 34. Oceanographic Research Institute, 44 pp.

Booth J.D. and R.A. Stewart. 1990. Distribution of phyllosoma larvae of the red rock lobster Jasus edwardsii off the east coast of New Zealand in relation to the oceanography. Bureau of Rural Resources Proceedings 15:138 -148.

Braine, S.J., D.W. Rimmer, and B.F. Phillips. 1979. An illustrated key and notes on the phyllosoma stages of western rock lobster Panulirus cygnus George. CSIRO Australian Division of Fisheries Oceanography Report, 102, 13pp.

Chow, S., H. Yamada, and N. Suzuki. 2006. Identification of mid- to final stage phyllosoma larvae of the genus Panulirus White, 1847 collected in the Ryukyu archipelago. Crustaceana 79:745-764.

Coutures, E. 2001. On the first phyllosoma stage of Parribacus caledonicus Holthuis, 1960, Scyllarides squammosus (H. Milne-Edwards, 1837) and Arctides regalis Holthuis, 1963 (Crustacea, Decapoda, Scyllaridae) from New Caledonia. Journal of Plankton Research 23:745-751.

Fisheries Statistics Book. 1999, 2000, 2001, 2002, 2003, 2004, 2005, 2006, 2008, and 2009. Ministry of Agriculture and Fisheries Wealth, Muscat.

Harris, R., P. Wiebe, J. Lenz, H.R. Skjoldal, and M. Huntley (Editors). 2000. ICES Zooplankton Methodology Manual, Academic Press. London.

Johnson, W.S. and D.M. Allen. 2005. Zooplankton of the Atlantic and Gulf Coasts: A Guide to their Identification and Ecology. JHU Press.

Igarashi, M.A. and J. Kittaka. 1994. Water quality and microflora in the culture water of phyllosomas. In: Spiny Lobsters: Fisheries and Culture. B.F. Phillips and J. Kittaka (Editors). Blackwell, Berlin.

Inoue, N., H. Minami, and H. Sekiguchi. 2004. Distribution of phyllosoma larvae (Crustacea: Decapoda: Palinuridae, 
Scyllaridae and Synaxidae) in the Western North Pacific. Journal of Oceanography 60:963-976.

Inoue, N., H. Sekiguchi, and S.P. 2001. Spatial distributions of phyllosoma larvae (Crustacea: Decapoda: Palinuridae and Scyllaridae) in Taiwanese Waters. Journal of Oceanography 57:535-548.

Kathirvel, M. 1990. On the collections of the phyllosoma larvae by Issaks-Kids midwater trawl from the west coast of India. In: Proccedings of the First Workshop Scientific Results of FORV Sagar Sampada, 141-146. 5-7 June 1989.

Lewis, J.B. 1951. The phyllosoma larvae of the spiny lobster Panulirus argus. Bulletin of Marine Science of the Gulf and Caribbean 1:89-95.

Liss, W.I., Williams R.N., Evans R.P., and N. Al-Raeisi. 1994. Genetic and life history variation in spiny lobster (Panulirus homarus) along the coast of Oman. Final Report to the Omani-American Joint Commission. Ministry of Agriculture and Fisheries, Oman.

Manzanilla-Domínguez, H. and R. Gasca. 2004. Distribution and abundance of phyllosoma larvae (Decapoda, Palinuridae) in the Southern Gulf of Mexico and the Western Caribbean Sea. Crustaceana 77:75-93.

Manzanilla-Domínguez, R.G. and E. Suárez-Morales. 2005. Notes on the distribution of phyllosoma larvae in an oceanic Atoll-like reef system in the Western Caribbean. Crustaceana 78:505 - 512.

Minami H., N. Inoue, and H. Sekiguchi. 2001. Vertical distributions of phyllosoma larvae of Palinurid and Scyllarid lobsters in the Western North Pacific. Journal of Oceanography 57:743-748.

Mujica, A. 2006. Decapod crustacean larvae from Juan Fernandez archipelago (33 $\left.{ }^{\circ} 40^{\prime} \mathrm{S}-78^{\circ} 50^{\prime} \mathrm{W}\right)$ and Desventuradas islands (26 $\left.26^{\circ} \mathrm{S}-80^{\circ} 05^{\prime} \mathrm{W}\right)$. Cienc. Tecnology Marine 29:137-152.

Murano, M. 1971. Five forms of palinurid phyllosoma larvae from Japan. Publications of the Seto Marine Biological Laboratory 19:17-25.

Pepin, P. and T.H. Shears. 1997. Variability and capture efficiency of bongo and tucker trawl samplers in the collection of ichthyoplankton and other macrozooplankton. Canadian Journal of Fisheries and Aquatic Sciences 54:765-773.

Phillips, B.F., P.A. Brown, D.W. Rimmer, and S.J. Braine. 1981. Description, distribution and abundance of late larval stages of the Scyllaridae (Slipper Lobsters) in the Southeastern Indian Ocean. Australian Journal of Marine and Freshwater Research 32:417-437.
Piontkovski, S.A., A.R. Al-Azri, and K.A. Al-Hashmi. 2012. Interannual changes of the Sea of Oman marine ecosystem. Open Marine Biology Journal 6:23-31.

Prasad, R.R., P.R.S. Tampi, and M.J. George. 1975. Phyllosoma larvae from the Indian Ocean collected by the Dana expedition 1928-1930. Journal of the Marine Biological Association of India 17:56-107.

Robertson, P.B. 1969. Phyllosoma larvae of a palinurid lobster, Justitia longimana (H. Milne Edwards) from the western Atlantic. Biological Investigations of the Deep Sea 49:923-943.

Sekiguchi, H. 1986a. Spatial distribution and abundance of phyllosoma larvae in the Kumano- and Enshunada seas north of the Kuroshio Current. Bulletin of the Japanese Society of Fisheries Oceanography 50: 289-297.

Sekiguchi, H. 1986b. Identification of late-stage phyllosoma larvae of the scyllarid and palinurid lobster in the Japanese waters. Bulletin of the Japanese Society for the Science of Fish 52:1289-1294.

Sheppard, C., M. Al-Husiani, F. Al-Jamali, and 21 others. 2010. The Gulf: a young sea in decline. Marine Pollution Bulletin 60:13-38.

Smith, S.L. 2005. The Arabian Sea of the 1990s: New biogeochemical understanding. Progress in Oceanography 65:113-115.

Suzuki, N., K. Hoshino, K. Murakami, H. Takeyama, and S. Chow. 2008. Molecular diet analysis of phyllosoma larvae of the Japanese spiny lobster Panulirus japonicus (Decapoda: Crustacea). Marine Biotechnology 10: 49-55.

Wiggert, J.D., R.R. Hood, S. Wigih, A. Naqvi, K.H. Brink, and S.L. Smith. 2009. Introduction to Indian Ocean biogeochemical processes and ecological variability: current understanding and emerging perspectives. In: Indian Ocean Biogeochemical Processes and Ecological Variability, J.D. Wiggert et al. (Editors), 1-9. American Geophysical Union. Washington.

Yeung, C., M.M. Criales, and T.N. Lee. 1995. Unusual larval abundance of Scyllarides nodifer and Albunea sp. during an intrusion of low-salinity Mississippi flood water in the Florida Keys in September 1993: insight into larval transport from upstream. Journal of Geophysical Research 105 (C12):28741-28758.

Received: February 12, 2012

Accepted: May 5, 2012 